\title{
A new tool for the optimal design of electrical cables in Wind Farms
}

\author{
A.A. Bayod Rújula ${ }^{1}$, R.Martínez ${ }^{2}$ \\ ${ }^{1}$ Department of Electrical Engineering \\ Centro Politécnico Superior, University of Zaragoza \\ C/ María de Luna, 3, 50018, Zaragoza (Spain) \\ phone:+34 97676 1920, fax:+34 97676 2226, e-mail: aabayod@unizar.es \\ ${ }^{2}$ Vestas Wind Systems A/S \\ Phone: +34 9765046 19, fax: +34 97650 5454, e-mail: romar@vestas.com
}

\begin{abstract}
In this paper, a new tool is proposed to design electric installations in wind farms. The structure of the wind farm is considered radial, as in most cases in wind farms, and the ratings of the cables are calculated, taking into account the technical constraints like electrical and thermal, and the economical aspects as cost of cable and energy savings for reduction of electrical losses. The program has been applied to solve the best rating of the cables in different wind farms and wind conditions, and the results are depictured.
\end{abstract}

Keywords: Energy saving, efficiency, losses, wind farms

\section{Introduction}

The design of electrical installations requires the satisfaction of many technical constraints like electrical, thermal and mechanical, taking into particular consideration the system operating costs. The cross section of the cables used in the transmission lines of a wind farm have to fulfil the current density limits given by the cable manufacturer. The project manager can decide to use the minimum cable size or choose a bigger section to reduce energy losses. Sometimes this decision is taken on the basis of cable availability. But it would be possible to calculate the best option in economic terms. That is, the cable size that achieves the optimum ratio between the increase in investment and the energy savings.

It is well known than usually the solution corresponding to the lower initial cost could be quite different from the solutions which optimize both the initial cost and energy savings for reduction of electrical losses, because of the relatively long life duration in time of the electrical installations (more than 20-25 years).
The main aim of the development of this program is to provide project managers with a tool to help take the decision on which cable size to use for each segment of the subterranean transmission line in a wind farm.

It would also provide a tool for those interested in researching the relationship that might exist between different wind profiles and the most suitable cable sizes.

\section{Characteristics of the program. Data input.}

The program allows the user enter, save and open different wind farm layouts. It also allows the user to enter, save and open different wind profiles both in tabular form and in terms of $\mathrm{A}$ and $\mathrm{K}$ factors in a Weibull distribution. The turbine power curve can be entered manually or chosen from a list of archives containing real data from some manufacturers. The cables to be used in the calculations can be entered manually in a tabular form. The program also provides a default table containing the most commonly used cables and its basic electrical specifications, along with approximate prices. Finally, we can modify the economic scenario by choosing the interest rate and the estimated lifespan of the park.

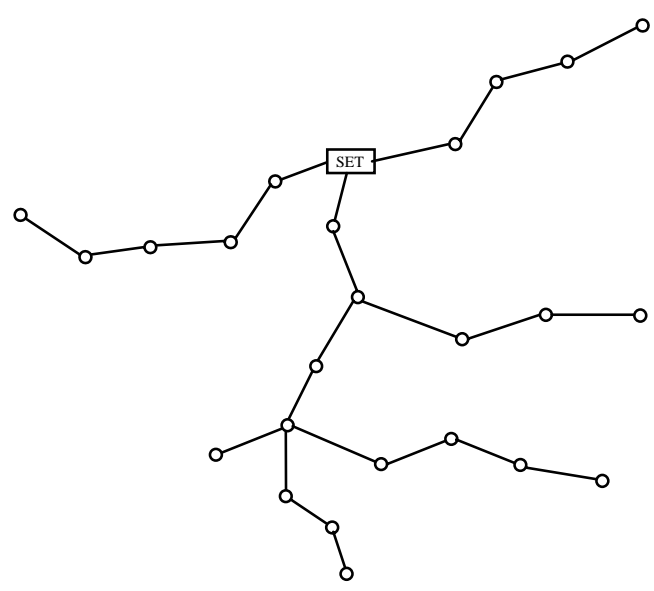

Figure 1. Wind farm layout 
There is no limit in the number of turbines in the wind park. The only layout permitted is a radial structure beginning from the substation. Each of the primary branches (those starting from the SET) may have an unlimited number of secondary branches. The same applies for tertiary branches beginning from any secondary branch. In order to get a well structured wind farm lay out and make it simple for new users to introduce data, it was decided to give every cable section three numbers which indicate to which primary, secondary and tertiary branch it belongs to. This means that a turbine with a 1.0.0 tag is placed in the first primary branch and does not belong to any secondary (nor tertiary) branch. This three numbers are not unique to each turbine. This means it is possible to find several turbines with the same tag. For the purpose of solely identifying a turbine a ID tag is given to each turbine. Finally, the length of the cable from the last turbine to the current one is requested in the form.

The turbine power curve can be introduced and stored in the Turbine Menu. It also allows the user select one of the existing commercial turbines.

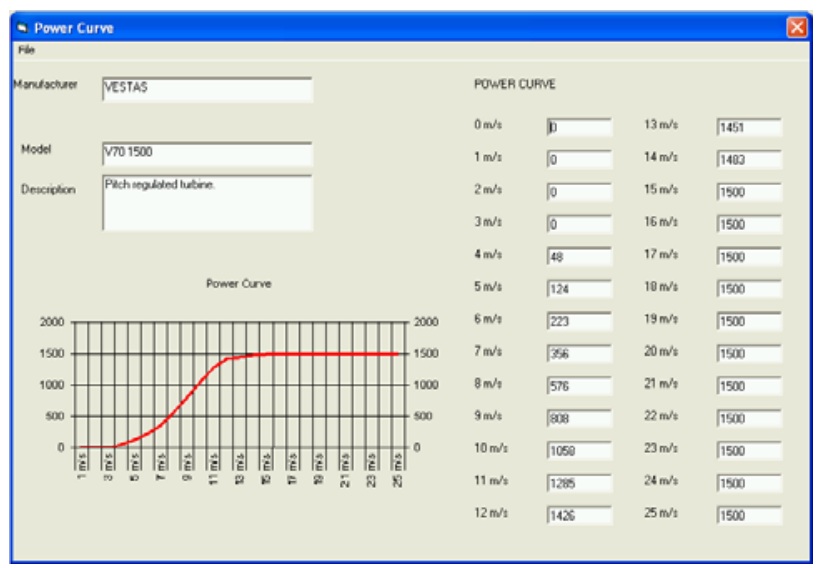

Figure 1. Power curve for VESTAS V70 1500Kw

In the next menu, wind distribution can be introduced both in form of percentages per wind speed and Weibull coefficients (A and K).

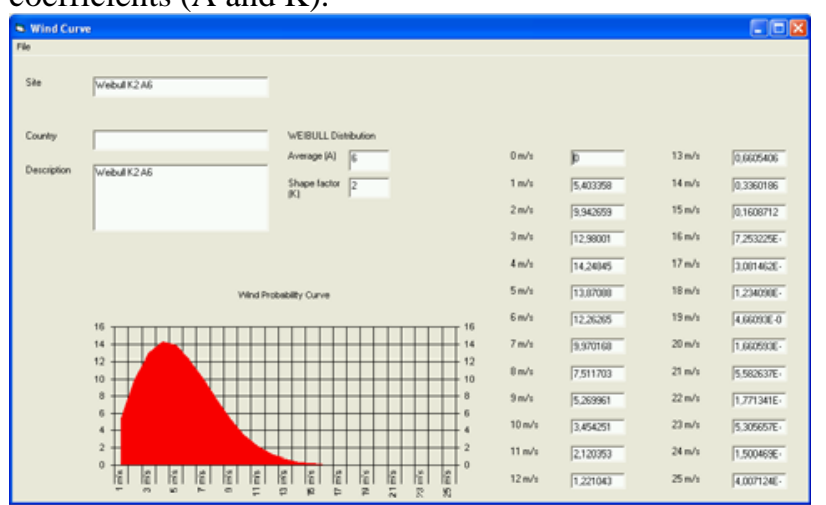

Figure 2. Wind distribution $(A=6, K=2)$

Different cable sets can be stored and retrieved. Next picture shows aluminium cables for $20 \mathrm{Kv}$.

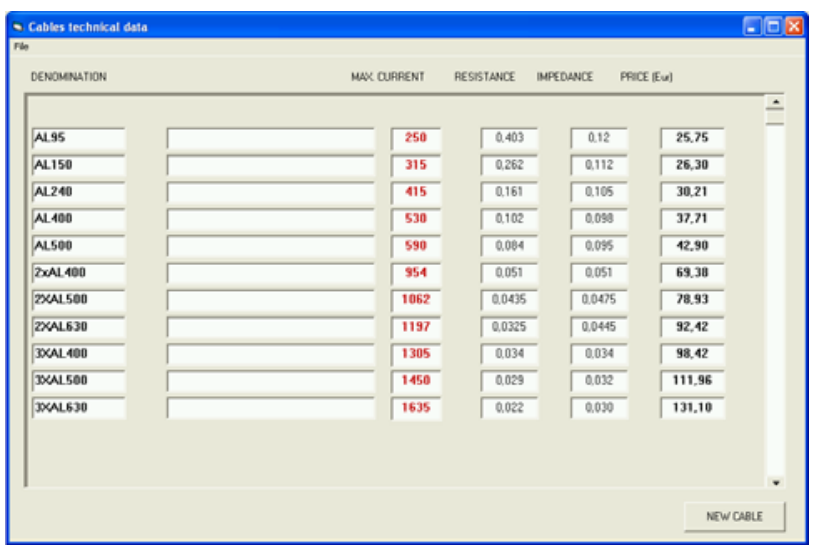

Figure 3. Set of cables for $20 \mathrm{Kv}$.

Besides, different financial scenarios can be used. Forecasted energy prices along the life span are as important as the current interest rate for the calculations.

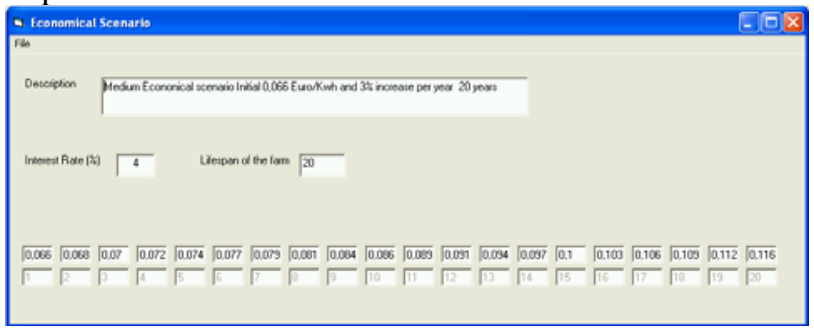

Figure 4. Financial scenario for 20 years.

\section{Calculations}

Once all the data has been fed into the system, the program will calculate the maximum current flowing through each of the segments

$$
I=\frac{\text { TurbinesPerSegment } \times P}{\sqrt{3} \times \cos \varphi \times V}
$$

the minimum cable size that complies with the current density will be chosen from the cable table. Then the both the individual voltage drop and accumulated voltage drop are calculated.

$\operatorname{Vdrop}(\%)=100 \times \frac{\sqrt{3} \times \text { Length } \times I \times(R \cdot \cos \varphi+X \cdot \operatorname{sen} \varphi)}{V}$

Energy losses throughout the expected life of the farm (supposed as 25 years) are also calculated for each of the cable segments.

$$
\text { E Losses }=3 \times \frac{N^{\mathrm{o}} \text { aero }^{2} \times R \times L \times 8760}{\sqrt{3}^{2} \times \cos \varphi^{2} \times U^{2}} \times \sum_{i=1}^{25} P i^{2} \times \% i
$$

These calculations would allow the program iterate in search for the most convenient cable section. There are two engines for changing cables. One is based in maximum individual voltage drop. The other is based in energy losses per kilometre. Both can be enabled simultaneously or separately. In this case the application will only change one cable at a time.

The value of the initial investment is calculated using the minimum cable sections that comply with current density values and the prices for cable installation given in the 
cables table. On every new iteration a new value is calculated and the extra investment is calculated subtracting the initial investment value from the last calculated value.

Investment (in million $€$ )

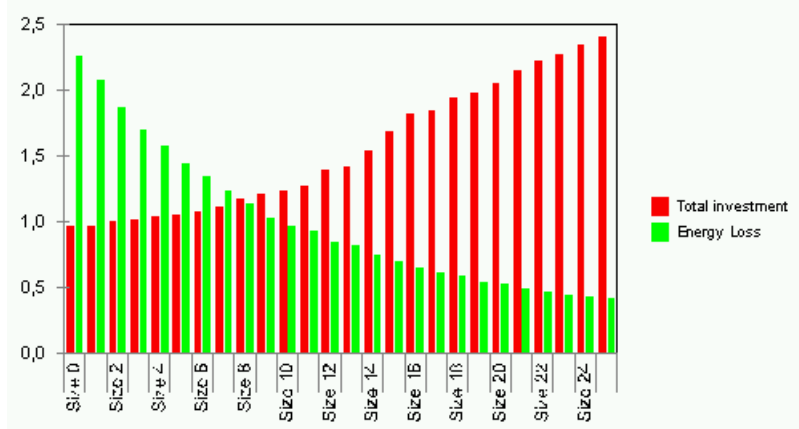

Figure 5. Investment and energy losses

At the same time, the program obtains new energy losses and "energy savings" are calculated subtracting these new losses from the initial value. This way, we are able to compare "energy savings" with the "extra investment" needed for bigger cables.

Energy Savings (in million $€$ )

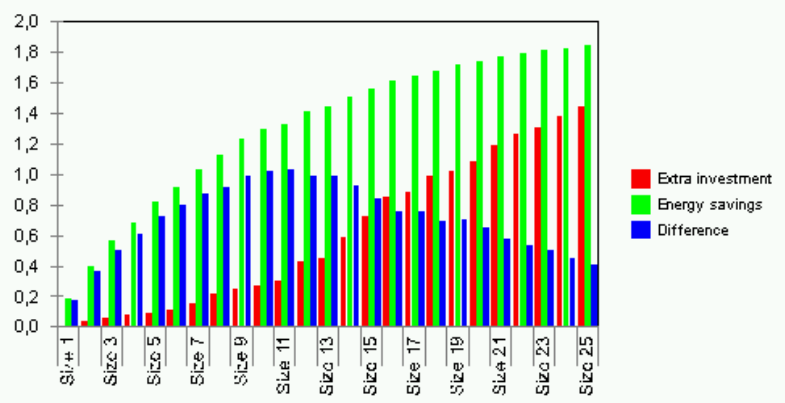

Figure 6. Energy savings

Finally, IRR and NPV values are obtained and shown in graphics.

IRR $(\%)$

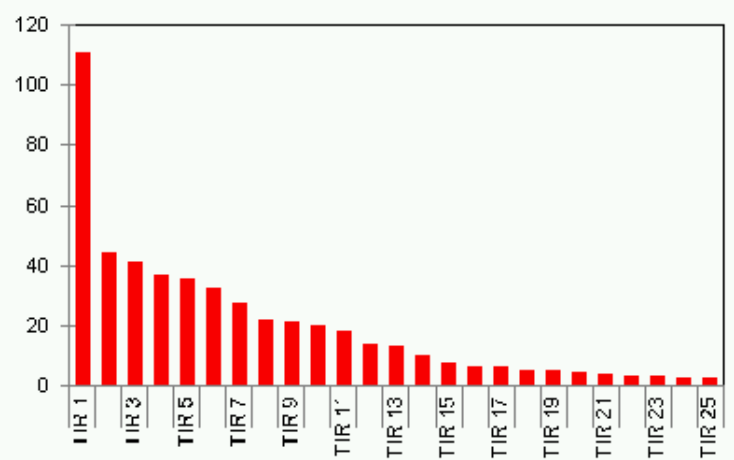

Figure 7. IRR for the extra investment

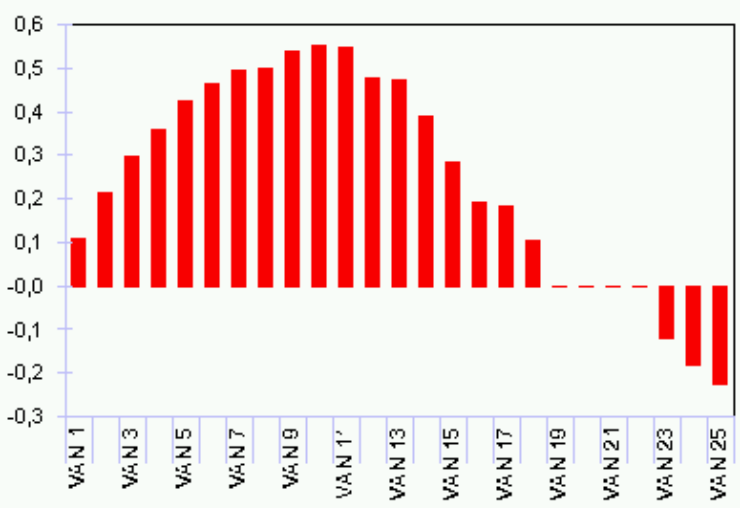

Figure 8. NPV for the extra investment

In another form, the exact values of IRR and VAN can be seen.

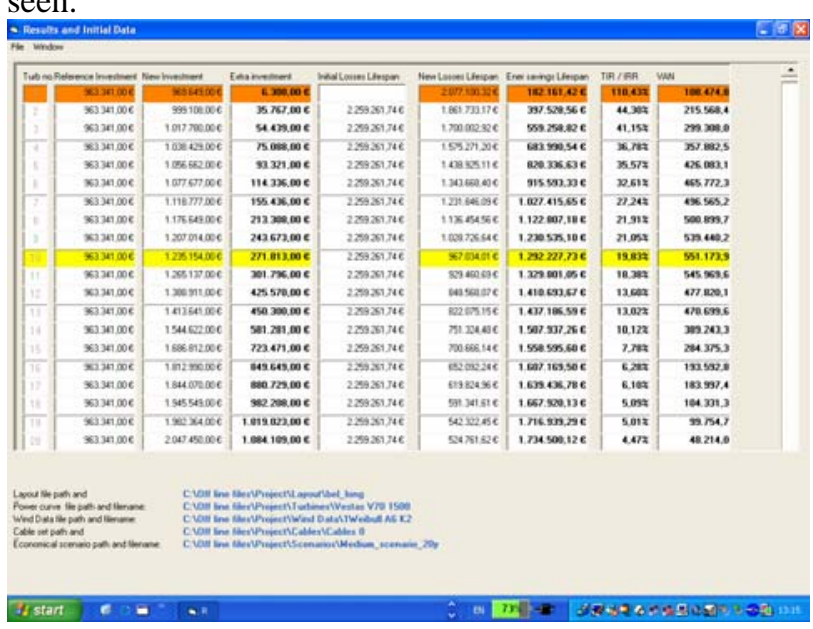

Figure 9. IRR and NPV in tabular form

The application allows users the variation of the values A and $\mathrm{K}$ of the Weibull distribution as well as the price of the energy and the price of cables.

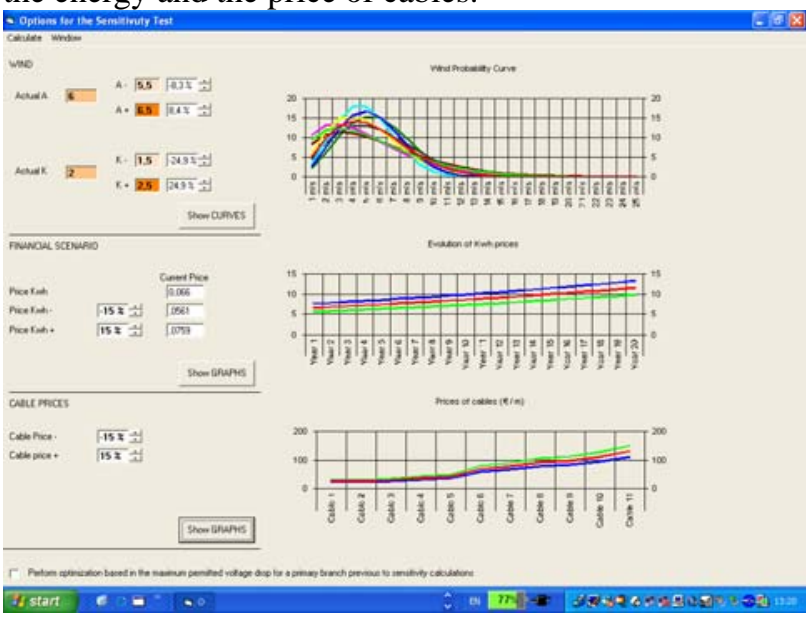

Figure 10. Variation of parameters

Comparative reports can be easily done when in search of general recommendations for certain wind distributions for a given park lay out. The number of iterations and the variation ratio can be changed in the Options Menu. 


\section{Case study}

Now a real layout is going to be used to show different results for different winds. Concretely, four different winds will be used:

- $\mathrm{A}=6, \mathrm{~K}=1.5$

- $\mathrm{A}=6, \mathrm{~K}=2$

- $\mathrm{A}=7, \mathrm{~K}=1.5$

- $\mathrm{A}=7, \mathrm{~K}=2$

The rest of parameters will remain unvaried:

- Voltage: $20 \mathrm{kV}$

- Financial scenario: medium, 20 years

- Previous calculations to achieve 3\% voltage drop: no

- Voltage drop change engine: enabled

- Energy losses change engine: enabled

- Number of iterations: 25

Next picture shows the layout.

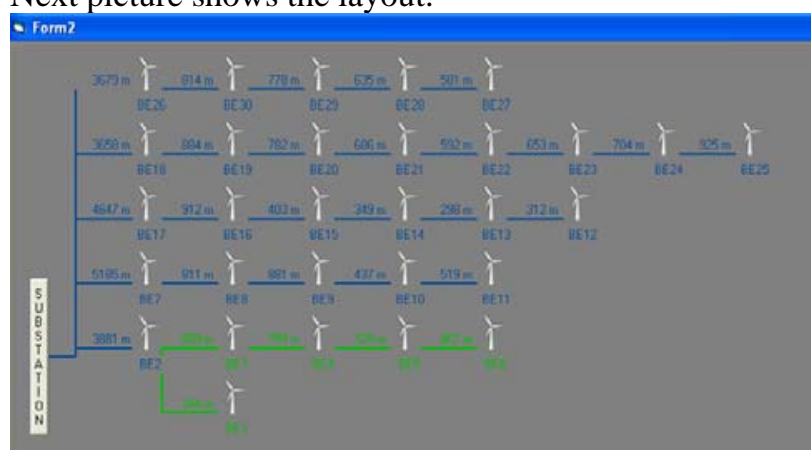

Figure 11. Typical wind farm layout

Next figures shows the values of energy savings obtained for the four different winds.

Energy Savings (in million $€$ )

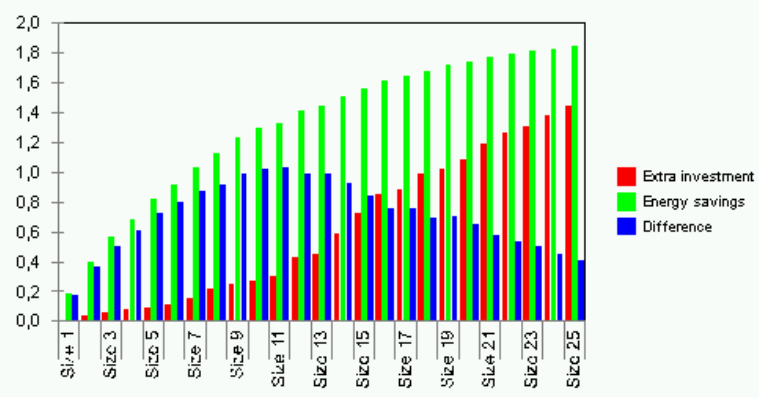

Figure 12. Energy saving for $A=6, K=2$

IRR (\%)

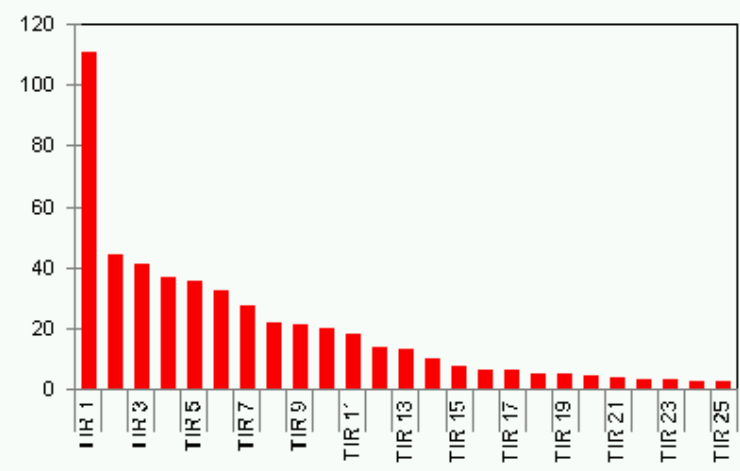

Figure 13. $I R R$ for $A=6, K=2$

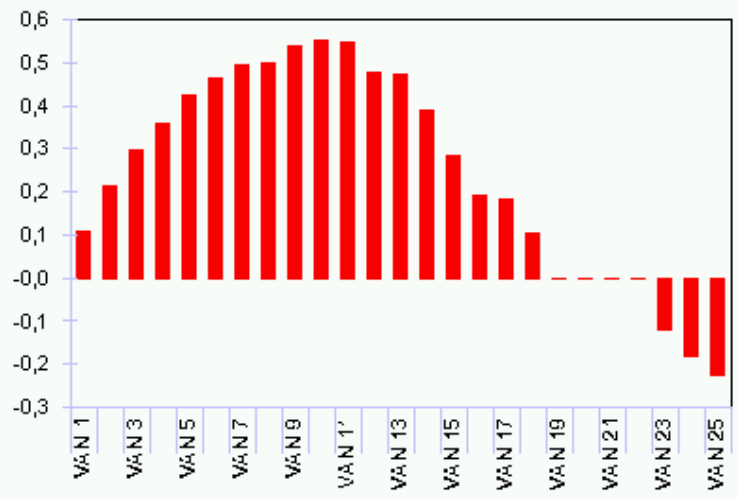

Figure 14. $N P V$ for $A=6, K=2$

Energy Savings (in million $€$ )

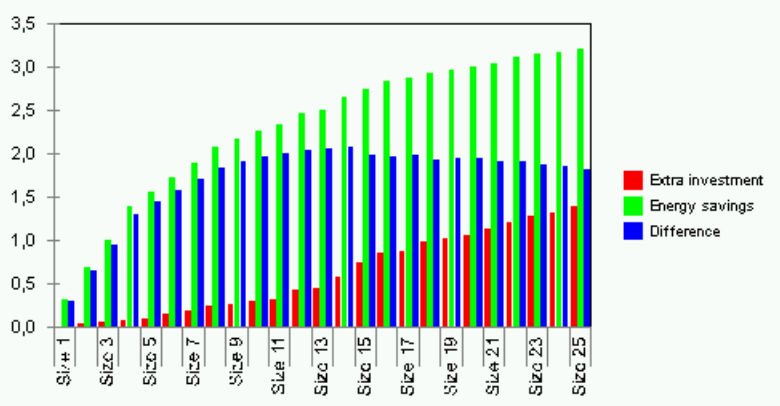

Figure 15. Enegy savings $A=7, K=2$

IRR $(\%)$

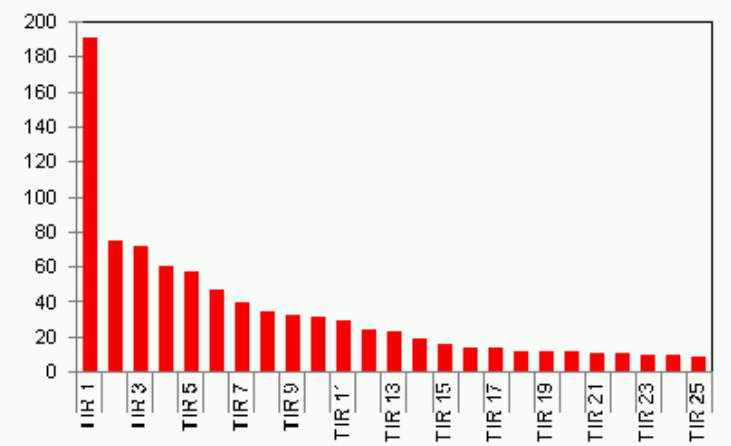

Figure 16. IRR for $A=7, K=2$

NPV (in million $€$ )

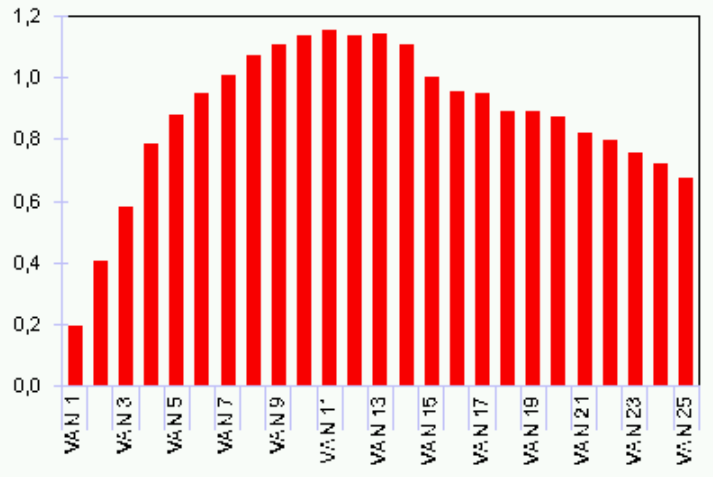

Figure 17. $N P V$ for $A=7, K=2$ 
Energy Savings (in million $€$ )

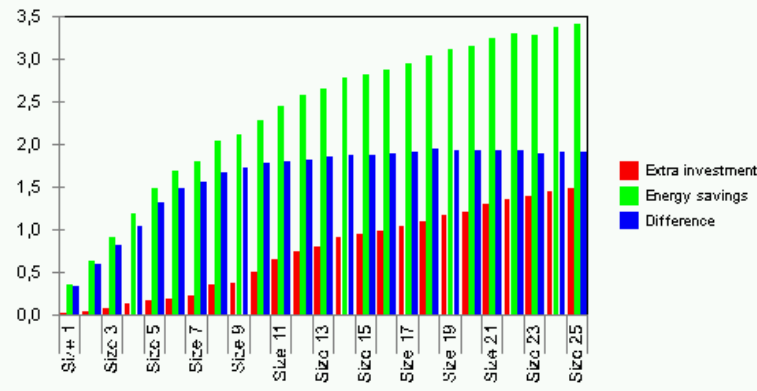

Figure 18. Energy savings for $A=7, K=1.5$

IRR $(\%)$

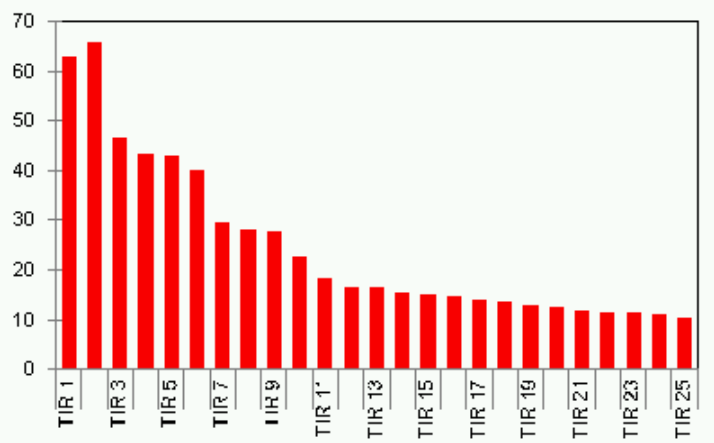

Figure 19. $I R R$ for $A=7, K=1.5$

NPV (in million $€$ )

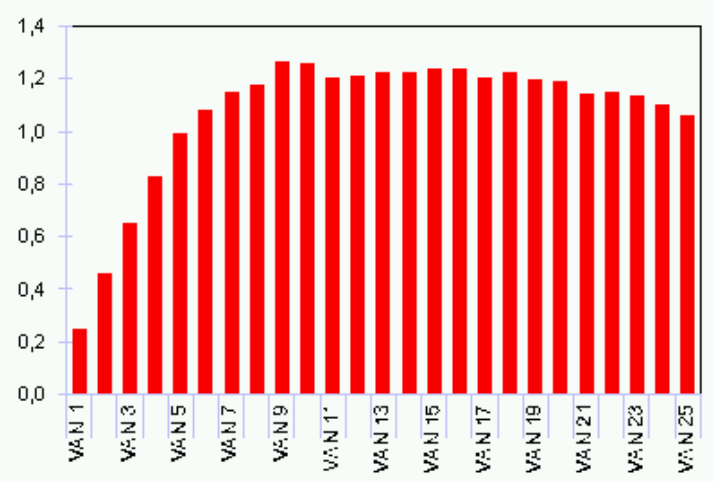

Figure 20. $N P V$ for $A=7, K=1.5$

Energy Savings (in million €)

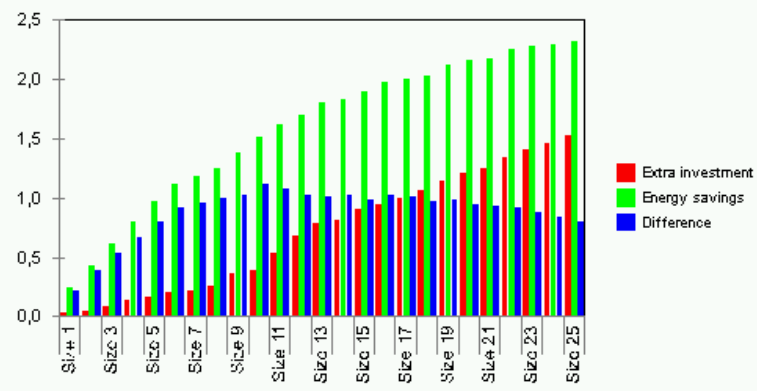

Figure 21. $N P V$ for $A=6, K=1.5$
IRR (\%)

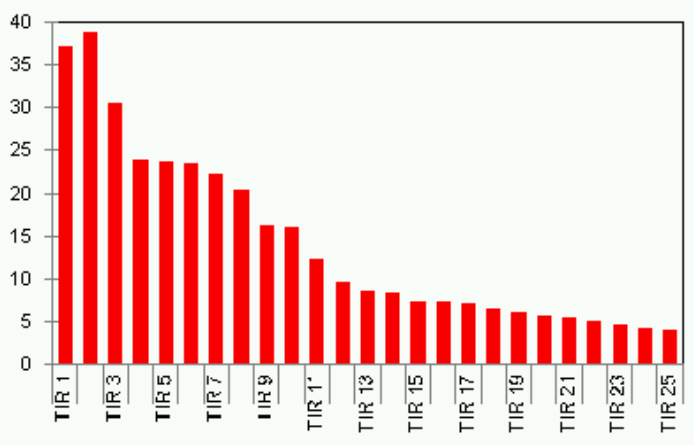

Figure 22. IRR for $A=6, K=1.5$

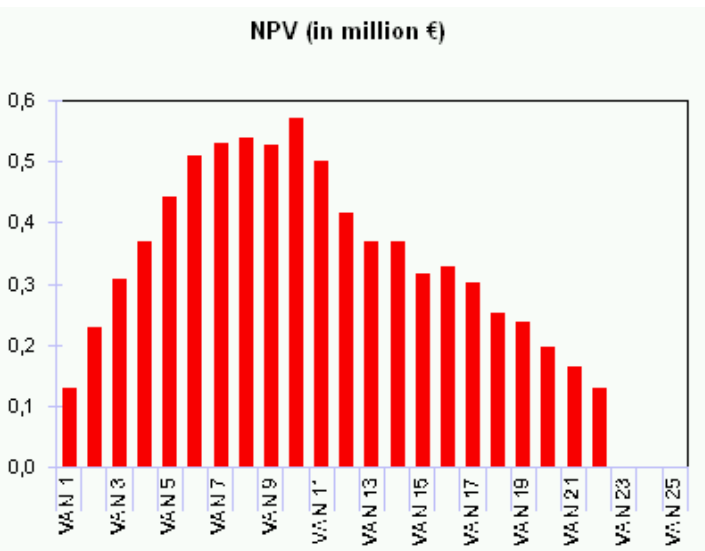

Figure 23. $N P V$ for $A=6, K=1.5$

Comparing results of NPV for $\mathrm{K}=6$ and $\mathrm{K}=7$ with $\mathrm{K}=2$ for both cases we can see that values are much higher for higher winds $(\mathrm{A}=7)$. Correspondingly, IRR values are also higher. So the conclusion is that the higher the winds, the more important is the choice of cables.

It is also noticeable that, at some point, values for NPV start decreasing and, for $\mathrm{A}=6$, become negative. The reason is that the investment is higher than the energy savings during the life span of the farm.

Financial results comparing the same Average factor $(\mathrm{A}=7)$ with $\mathrm{K}$ factors of 2 and 1.5 do not show a big difference in terms of the NPV achieved (around 1,2 mEuros). The same conclusion applies when comparing winds with $\mathrm{A}=6$.

\section{References}

[1] A. Canova, F. Profumo, M. Tartaglia, LCC Design Criteria in Electrical Plants Oriented to the Energy Saving, Proc. IEEE Tr.on Industry Applications, Vol 39, $n^{\circ} 1$, Jan-Feb 2003, pp. 53-58

[2] S. Fernández Uranga, Red de Media Tensión de un parque eólico

[3] UNE 211441-1-1, Cables eléctricos. Cálculo de la intensidad admisible. Parte 1: Ecuaciones de intensidad admisible (factor de carga 100\%) y cálculo de pérdidas. 
[4] Strbac, G., Jayantilal, A, Allan, R.N., Jenkins, N. Allocation of losses in electrical distribution systems with wind generation, Proc. Of the 1996 European Union conference on Wind energy, Goteborg, 1996. 